\title{
How do changes in lifestyle complement medical treatment in heart failure?
}

\footnotetext{
Servicio de

Cardiologia, Hospital

General Universitari

Vall d'Hebron,

Barcelona, Spain

J Soler-Soler

G Permanyer-Miralda

Correspondence to:

Dr J Soler-Soler,

Servicio de Cardiologia,

Hospital General

Universitari Vall d'Hebron,

Passeig Vall d'Hebron

119-129, 08035 Barcelona,

Spain.
}

\author{
J Soler-Soler, G Permanyer-Miralda
}

Heart failure not only has a poor prognosis but impairs the quality of life. Research on pharmacological treatments continues to try to improve the prognosis and symptoms of patients with heart failure. However, nonpharmacological measures such as rest and dietary salt restriction have been used to treat heart failure since the time when available drug treatment was limited to digitalis or some rudimentary type of diuretic. Despite dramatic advances in drug treatment, advice on modifying lifestyle still plays an important part in the treatment of a condition which itself influences lifestyle so much.

Modifications of the lifestyle of patients with heart failure may take three different and sometimes conflicting directions: (a) avoidance of harmful habits (excess sodium intake, smoking, alcohol consumption), (b) enhancement of wellbeing (limitation of symptom provoking activity, psychological education for a better acceptance of untreatable limitation), and $(c)$ promotion of favourable changes in neuroautonomic function, muscular status, and peripheral circulation through physical training. The relative emphasis to be laid on the second or third approaches depends on the patient's condition and overall prognosis. There are patients who, at best, can hope to be free of only the most severe discomfort whereas, in others, to achieve a fairly good or even virtually normal quality of life is a realistic goal.

The areas where lifestyle modification has been advocated for the management of heart failure include diet; the avoidance of toxic habits; physical activity; and psychological adjustment. The evidence on which advice should be given is variable in quality and quantity, and clinicians may be left with little more than common sense for guidance. As in other "common sense" medical approaches, however, experimental research sometimes contradicts what seems obvious - for example, physical activity.

\section{Diet}

Dietary advice in heart failure has traditionally concentrated on sodium restriction. Sodium restricted diets were introduced at the beginning of the century, ${ }^{1}$ based on the knowledge that in heart failure there is avid sodium reabsorption by the kidney, and the rationale that dietary sodium restriction should favourably affect sodium balance. Thus a diet low in sodium became one of the mainstays of treatment. ${ }^{2-4}$ Well into the 1960 s diets with as low a sodium content as $0.5 \mathrm{~g} /$ day were recommended. ${ }^{3}$ Progressively, this stringent approach gave way to a more liberal daily sodium intake $\left(2-3 \mathrm{~g} / \mathrm{day}^{5}{ }^{6}\right)$ on the assumption that sodium and water retention could be countered by concomitant judicious diuretic treatment without serious side effects. Despite advances in drug treatment, moderate to appreciable sodium restriction is still considered one of the cornerstones of the treatment of heart failure by many authorities ${ }^{67}$ and is included in current workshop recommendations. ${ }^{8}$ However, in two recent surveys of doctors' practice in the management of heart failure, one from the United States ${ }^{9}$ and the other from Europe, diet was the first therapeutic measure in only two out of five countries. ${ }^{10}$ Some recent reviews on treatment of heart failure do not even mention dietary sodium restriction. ${ }^{11}$

Few modern studies have examined the effects of a low sodium diet in patients with heart failure, ${ }^{12}$ and even then the emphasis is on the neuroendocrine or metabolic rather than clinical effect. Severe sodium restriction activates the renin-angiotensin system and sympathetic nerve activity. ${ }^{12}$ One reason for the paucity of clinical studies on low sodium diet may be the difficulty in carrying out trials with acceptable measurement of dietary sodium intake outside institutional settings. On the other hand, studies conducted on a metabolic ward may be irrelevant to common clinical practice. Another powerful reason is that the effectiveness of a low sodium diet as a general measure might be considered to be too evident to warrant further investigation.

Excessive sodium retention by the kidneys has been consistently shown to be a feature of heart failure ${ }^{13-15}$ - possibly an inappropriate renal response to a fall in cardiac output ${ }^{16}$ and this is the rationale for sodium restriction. Abnormal handling of sodium is a marker of even mild heart failure: Volpe et al recently showed that in patients with left ventricular dysfunction but not in normal subjects atrial natriuretic factor concentration fails to rise in response to a sodium load and sodium retention occurs. ${ }^{17}$ They suggested that their findings indirectly supported the usefulness of sodium restriction. However, noticeable differences in avidity for sodium retention during a low sodium diet in patients with heart failure have been found, ${ }^{12}$ suggesting the possibility of different optimal regimens in haemodynamically similar patients. In addition, the effect of diuretic treatment can be reduced in subjects given a low sodium diet, ${ }^{18}$ thus raising the issue of the appropriateness of stringent sodium reduction when diuretics are given.

In fact, despite the apparently universal consensus on the desirability of a low sodium 
diet, information on the influence of sodium restriction on the long term outcome in different clinical settings, with different concomitant treatments, and even in different patients is not available. One report suggests that heart failure due to abnormal left ventricular relaxation in salt sensitive patients with hypertension might be more dependent on sodium induced volume overload. ${ }^{19}$ Sodium could be regarded as an actual cause of heart failure in such cases. Even if not directly related to diet, research on the relation between sodium and heart disease is growing. ${ }^{20}$

Emphasis on the need to restrict dietary sodium in heart failure is justified for doctors on the basis of its effectiveness (even if some aspects deserve further clarification). Although doctors' contribution to changing general dietary habits in this way is small, there is increasing evidence for the need to limit sodium intake in the Western population to prevent hypertension, a leading cause of heart failure..$^{2021}$ The detection of salt sensitive subjects should be relevant in this context. ${ }^{19} 20$ Thus restricting dietary sodium may be useful in preventing as well as treating heart failure. A reasonably low sodium intake (about $2 \mathrm{~g} /$ day) can usually be achieved by the patient with easily acceptable changes in dietary habits. $^{57}$

An additional way to facilitate the tailoring of sodium restriction is to educate patients into the habit of measuring their diuresis and their weight. Two other well known practical points should also be kept in mind. Firstly, further reductions in sodium intake (down to 0.5$1 \mathrm{~g} /$ day), even if more difficult to carry out, may improve symptoms in severe or refractory cases. Secondly, it is important to prevent binging on salt, which may result in acute severe decompensation. ${ }^{6}$ Poor compliance with a low sodium diet has been reported as one of the causes for emergency admission to hospital in patients with chronic heart failure. ${ }^{22}$ Efforts to keep dietary sodium low, however, should not result in an insufficient energy intake leading to poor nutritional status. If palatable, salt substitutes can prove to be an alternative approach, care being required to ensure that they are really sodium free.

An issue to be raised is the safety of a low sodium diet. Uraemia associated with sodium depletion was reported as early as $1949 .{ }^{3}$ In many instances, however, it resulted more from the injudicious use of diuretics than from sodium restriction. The occurrence of acute renal dysfunction, with uraemia and hyperkalaemia, is a well known complication of overzealous treatment of heart failure with diuretics resulting in excessive sodium and volume depletion, ${ }^{15}$ particularly in vulnerable patients (such as elderly people or those with previous renal or arterial disease in whom renal regulatory mechanisms may be blunted ${ }^{15}$ ). Elderly people may be particularly prone to poor acceptance and side effects of moderate to marked sodium restriction (appetite loss, asthenia, and confusion)..$^{23} 24$ The introduction and widespread use of ACE inhibitors is another potential cause of renal dysfunction. ${ }^{25}$ ACE inhibitors reduce the efferent glomerular arteriolar tone, which may result in renal dysfunction, particularly in previously hypertensive patients whose blood pressure has been appreciably reduced, ${ }^{26}$ even when they do not have renal artery stenosis. ${ }^{27}$ This problem is not uncommon in patients with severe acute heart failure who have been overtreated with diuretics and ACE inhibitors. $^{25}$ The contribution of low dietary sodium is difficult to assess. Acute volume losses such as induced by diarrhoea ${ }^{28}$ may result in unduly severe renal dysfunction if ACE inhibitors have blocked the physiologically protective renin-angiotensin system.

\section{Avoidance of harmful habits}

In view of the deleterious effects of smoking on the cardiovascular system and respiratory function, it is obvious that patients with heart failure should not smoke. It is also common practice to forbid alcohol consumption because it may acutely depress ventricular performance. $^{29}$ In addition, cessation of excessive intake may result in improvement of depressed systolic function. ${ }^{30}$ In cases of heart failure clearly not associated with alcohol abuse, however, the psychological consequences of depriving patients of the pleasure of a modest amount of alcohol probably outweigh the questionable long term benefits of abstinence, especially in countries where moderate wine drinking during meals is a widespread habit.

\section{Physical activity}

The promotion of physical activity is the greatest recent change advocated for the treatment of heart failure. Classically, rest was emphasised as it seemed obvious that, as the heart was unable to meet the body's needs, these should be kept to a minimum to decrease cardiac work. As early as the 1960 s, however, recommendations ${ }^{3}$ for prolonged bed rest were already being questioned ${ }^{4}$ and resumption of moderate symptom free activity was encouraged after compensation had been reached. Research suggested that excessive rest might be harmful by causing muscular deconditioning, whereas exercise programmes resulted in fewer symptoms during everyday activities. Controlled exercise programmes were considered beneficial to the myocardial and muscular circulation, particularly in patients with coronary disease. ${ }^{5}$ Now exercise is being recommended as a therapeutic intervention for heart failure, at least in selected patients. Some of the features of recent studies on physical exercise in heart failure are relevant to the present discussion.

(1) As mentioned, active physical training may be beneficial in cardiac failure. Training has been consistently shown to improve symptoms, exercise capacity, and peak oxygen uptake and to reduce ventilatory drive during submaximal and maximal exercise. ${ }^{31-35}$ No complications-for example, exercise induced 
arrhythmia-were recorded in these selected populations of patients. Information on long term outcome is lacking, but there is speculation that physical training may result in improved survival, ${ }^{36}$ as one of the variables shown to predict mortality (low exercise capacity ${ }^{37}$ ) can be reversed, and that the enhanced survival with vasodilator treatment may, in part, be mediated by the improved exercise capacity and physical activity brought about by such drugs. ${ }^{36}$ Therefore, rest is no longer considered appropriate treatment for heart failure in compensated cases. ${ }^{35} 38$

(2) Such studies contribute to a better understanding of some of the clinical and pathophysiological features of heart failure. In the above mentioned studies, no improvement in systolic function was found after training. ${ }^{31} 33$ Rather, improved performance was associated with evidence of improved oxygen delivery to peripheral tissues, reduced arteriovenous difference in lactate concentrations, and increased lactate utilisation. ${ }^{31}$ Evidence that muscle enzymatic and histological abnormalities occur in heart failure, either from deconditioning alone or from heart failure itself, ${ }^{36}$ is well known. ${ }^{39} 40$ Training seems to improve muscle function and reverse the impaired oxidative capacity of muscle in heart failure. ${ }^{41}$ Most importantly, in one study a significant shift towards reduced sympathetic and enhanced vagal activities achieved by training was shown by power spectral analysis of RR interval variability and noradrenaline kinetics. ${ }^{35}$ This improvement in abnormal sympathovagal balance may improve circulatory function and reduce arrhythmias and sudden death.

(3) These studies have also shed light on the differences between maximal exercise testing (measuring aerobic capacity and thus overall cardiopulmonary function) and submaximal exercise, ${ }^{31} 3842$ which is more similar to the situation encountered during everyday activities. Training studies have helped explain some apparent discrepancies such as why patients with good aerobic capacity experience excessive fatigue after exercise. ${ }^{42}$

Patients with heart failure should be encouraged to exercise regularly within their capabilities. The time may have come for routinely prescribing formal exercise training to patients with compensated heart failure, although the resources required to do this safely and effectively must not be underestimated. The available studies suggest that controlled physical training programmes improve symptoms and exercise capacity, implying that a more active lifestyle can be adopted. However, the safety and benefit of uncontrolled vigorous activity has not been determined.

Some considerations regarding the exercise studies should be kept in mind:

(1) The populations from which the study patients were drawn were not precisely characterised and, as a rule, the clinical features of the study patients were not extensively reported.

(2) The studies do not permit assessment of whether the effects of training apply equally to coronary artery disease and to other types of heart disease.

(3) The results of exercise training in heart failure due to diastolic dysfunction have not been addressed.

(4) Although the need to categorise patients by their haemodynamic features to predict the outcome of exercise training is recognised, ${ }^{42-44}$ no specific criteria have been established for selection. Scalvini et al have suggested that oxygen uptake of less than $16 \mathrm{ml} / \mathrm{kg} / \mathrm{min}$ at the peak workload of exercise testing could identify a severe subgroup less likely to benefit from training. ${ }^{34}$ Such findings should be further evaluated-as well as the value of simple clinical variables - as guidelines for entering a training programme. Clinical contraindications to training should also be kept in mind. ${ }^{43}$

(5) A standard exercise protocol for adequate evaluation and discrimination of all patients with heart failure is considered by some experts not to be available ${ }^{44}$; in addition, the issue of whether some type of isometric training is advisable for these patients has not been addressed as all published studies deal with dynamic aerobic exercise. ${ }^{45}$

(6) As previously stated, no long term information about patients undergoing training is available; adverse long term effects of exercise have not yet been ruled out.

(7) Studies have been performed in specialised institutions and sophisticated laboratories, with a particular emphasis on physiological measurements (although, remarkably, in the study by Coats et al the training programme was performed at the patients' home and not directly supervised ${ }^{35}$ ). Adequate information from community settings and less selected populations would be desirable.

The research on exercise programmes suggests that more liberal counselling regarding vocational rehabilitation, return to work, recreational activity, and sexual habits is warranted in patients with heart failure. Until more information is available clinicians should advise patients individually on how much exercise they should take. Resumption of an active lifestyle may improve the psychological outlook. Some decisions - for example, those regarding returning to work-require clinical judgment of the functional status of patients, their psychological demands (or economic needs), and the activity under consideration.

\section{Psychological adjustment}

When patients have been systematically assessed in quality of life studies, emotional distress, anxiety, depression, and psychosocial maladjustment are prevalent in heart failure. ${ }^{46-49}$ Improvement has been reported in response to treatment for heart failure, ${ }^{47}$ but occasional patients may benefit from psychiatric care. Exercise training may improve the psychological outlook and self confidence of patients. ${ }^{35}$ Psychological adjustment to the lifestyle imposed by the disease usually 
requires the patient, the family, and the health care professionals to be fully informed..$^{50}$

The need for supportive care is increasingly recognised, as is the case with patients after cardiac surgery or myocardial infarction..$^{50}$ The role of nursing staff may be important in helping patients to participate in a normal daily life, improve their psychosocial adjustment, and comply with medical advice. $^{151}$ Nursing staff may also help family members to cope. ${ }^{151}$ More research is required on these types of intervention, both in hospital and in the community.

\section{Measurement of quality of life}

To assess the effects of modifying lifestyle we should know how to measure them. ${ }^{47-49} 5253$ One goal is to have objective evaluations of how and how much heart failure influences patients' lives and of how patients cope with disease. These evaluations may be useful as baseline and outcome measures and should provide a framework to determine the impact of any change on patients' quality of life.

Although there have been advances in the measurement of quality of life in heart failure during recent years, methodological problems remain, and it is premature to advocate its use for clinical purposes in individual patients. The achievement in quality of life measurement in heart failure can be summarised as follows: (a) general profiles of populations with heart failure in terms of quality of life have been developed ${ }^{46} 475$; (b) the validity of the measuring instruments has been tested $^{484954}$ and correlated with clinical outcome ${ }^{474954}$; and (c) the need to include quality of life studies as outcome measures in clinical trials such as SOLVD has been recognised. 48495556

Problems in measuring the quality of life of patients with heart disease have been recognised for years. ${ }^{52}{ }^{57}$ In view of the insufficiency of simple activity scales such as that of the New York Heart Association or similar classifications, ${ }^{5859}$ the development of better measuring instruments is required. The ideal instrument should be a valid, reproducible, and sensitive to change measure of symptoms, activity, and emotional and psychological status. ${ }^{52}$ Several questionnaires and analogue scales have been devised for this purpose. ${ }^{4956} 60-62$ Some of them, such as the Minnesota living with heart failure questionnaire, have been validated in more than one large clinical trial, ${ }^{49}{ }^{55}$ whereas others, such as the chronic heart failure questionnaire, ${ }^{61}$ are included as outcome measure instruments in trials now under way. Despite the initial reports on validation and reliability, further experience is required before these measures can be widely accepted. A recent substudy of the SOLVD trial included no less than nine quality of life instruments to be administered to each patient. ${ }^{48}$ Obviously, such a complex procedure is irrelevant for routine clinical practice. Even for clinical research, a simpler, less cumbersome method is desirable.
1 Michaelson CR. Congestive heart failure. St Louis, Missouri: CV Mosby, 1983:354-99.

2 Blumgart HL, Zoll PM. The clinical management of congestive heart failure. Circulation 1960;21:218-28.

3 Wood P. Diseases of the heart and circulation. London: Eyre and Spottiswoode, 1968:325-46.

4 Benack RT. Congestive heart failure. Springfield, ILL: Charles C Thomas, 1966:54-86.

5 Myerson RM, Pastor BH. Congestive heart failure. St Louis, MI: CV Mosby, 1967:90-136.

6 Cohn JN. Current therapy of the failing heart. Circulation 1988;78:1099-107.

7 Smith RW, Braunwald E, Kelly RA. The management of heart failure. In: Braunwald E, ed. Heart disease. $A$ textbook of cardiovascular medicine. Philadelphia: Saunders, 1992:468.

8 Expert Group on Treatment of Heart Failure. Recommendations from the group. In: Workshop: pharmacological treatment of heart failure. Uppsala: Medical Products treatment of heart fallur.

9 Hlatzky MA, Fleg JL, Hinton PC, et al. Physician practice in the management of heart failure. $\mathcal{f} \mathrm{Am}$ Coll Cardiol in the managem

10 Olshausen KV, Erbel R, Perkins CM, Brogard JM. Diagnosis and treatment of heart failure in different european countries: a young AEMIE quesionnaire. $A n n$ Med Interne (Paris) 1986;137:226-8.

11 Packer $M$. Treatment of chronic heart failure. Lance 1992;340:92-5.

12 Cody RJ, Covit AB, Schaer GL, Laragh JH, Sealey JE, Feldschuh J. Sodium and water balance in congestive heart failure. $\mathcal{F}$ Clin Invest 1986;77:1441-52.

13 Packer M. Pathophysiology of chronic heart failure. Lancet 1992;340:88-92.

14 Harris P. Role of arterial pressure in the oedema of heart disease. Lancet 1988;i:1036-8.

15 Badr KF, Ichikawa I. Prerenal failure: a deleterious shift from renal compensation to decompensation. $N$ Engl $f$ Med 1988;319:623-9.

16 Cleland JGF, Dargie HJ. Heart failure, renal function and angiotensin converting enzyme inhibitors. Kidney Int 1987;31(suppl 20):S220-80

17 Volpe M, Tritto C, DeLuca N, et al. Abnormalities of sodium handling and of cardiovascular adaptations sodium handling and of cardiovascular adaptations during high salt diet in patient

18 Good J, Frost G, Meek J, Oakley C, Cleland J. Sodium restriction impairs a frusemide-induced diuresis in patients with heart failure [abstract]. Eur Heart $\mathfrak{f}$ 1992;13(suppl):217.

19 Sullivan JM, Ratts TE, Taylor JC, et al. Hemodynamic effects of sodium in man: a preliminary report. Hypertension 1980;2:506-14

20 Soberman JE, Sullivan JM. New thinking about sodium and the heart. Current Opinion in Cardiology 1993, 8:728-36.

21 Rose G. The strategy of preventive medicine. Oxford: Oxford University Press, 1992.

22 Wagdi P, Vuilliuomenet A, Kaufmann U, Richter M, Bertel O. Ungenugende Behandlungdisziplin, Patienteninformation und Medikamentenverschreibung als Ursachen fur die Notfallhospitalisation bei chronisch 1993;123:108-12

23 Berkman $M$, Tran $M$. Le sujet âgé, le régime sans sel et les diurétiques. Semaine des Hôpitaux (Paris) 1978;54: diuretiques.

24 Belmin J. Low sodium diet and congestive heart failure in the elderly. $\mathcal{f}$ Am Geriatr Soc 1992;40:298-9.

25 Cleland JGF. Adverse reactions and drug interactions with ACE inhibitors. In: Cleland JGF, ed. The clinician's guide to $A C E$ inhibition. Edinburgh: Churchill Livingstone, 1993:179-97.

26 Toto RD, Mitchell HC, Lee HC, Milam C, Pettinger WA. Reversible renal insufficiency due to angiotensin converting enzyme inhibitors in hypertensive nephrosclerosis. Ann Intern Med 1991;115:513-9.

27 Bridoux F, Hazzan M, Pallot JL, et al. Acute renal failure after the use of angiotensin-converting-enzyme inhibitors in patients without renal artery stenosis. Nephrol Dial Transplant 1992;7:100-4.

28 McMurray J, Matthews DM. Effect of diarrhoea in a patient taking captopril. Lancet $1985 ; \mathrm{i}: 581$.

9 Horwitz LD, Atkins JM. Acute effects of ethanol on left ventricular performance. Circulation 1974;49:124-8.

30 Pavan D, Nicolosi GL, Lestuzzi C, Burelli C, Zardo F, Zanuttini $D$. Normalization of variables of left ventricular
function in patients with alcoholic cardiomyopathy after function in patients with alcoholic cardiomyopathy after
cessation of excessive alcohol intake: an echocessation of excessive alcohol intake: an

31 Sullivan MJ, Higginbotham MB, Cobb FR. Exercise training in patients with severe left ventricular dystraining in patients with severe left ventricular dys-
function: hemodynamic and metabolic effects. Circulation function: hemodyna

32 Sullivan MJ, Higginbotham MB, Cobb FR. Exercise training in patients with chronic heart failure delays
ventilatory anaerobic threshold and improves subventilatory anaerobic threshold and improves submaximal

33 Koch M, Douard H, Broustet JP. The benefit of graded exercise in chronic heart failure. Chest 1992; 101(suppl):231-5S

34 Scalvini S, Marangoni S, Volterrani M, Schena M, Quadri A, Levi GF. Physical rehabilitation in coronary patients 
who have suffered from episodes of cardiac failure. Cardiology 1992;80:417-23

35 Coats AJS, Adampoulos S, Radaelli A, et al. Controlled trial of physical training in chronic heart failure: exercise performance, hemodynamics, ventilation, and autonomic function. Circulation 1992;85:2119-31.

36 Minotti JR, Massie BM. Exercise training in heart failure patients. Does reversing the peripheral abnormalities protect the heart? Circulation 1992;85:2323-5.

37 Szlachcic J, Massie BM, Kramer BL, Topic N, Tubau J. Correlates and prognostic implication of exercise in chronic congestive heart failure. Am f Cardiol 1985; 55:1037-42.

38 Shabetai $R$. Beneficial effects of exercise training in compensated heart failure. Circulation 1988;78:775-6.

39 Lipkin DP, Jones DA, Round JM, Poole-Wilson PA. Abnormalities of skeletal muscle in patients with chronic heart failure. Int $\mathcal{f}$ Cardiol 1988;18:187-95.

40 Schaufelberger $M$. Skeletal muscle metabolism and the effect of physical training in congestive heart failure. In: Workshop: pharmacological treatment of heart failure. Uprkshop: pharmacological treatment of heart

41 Adamopoulos S, Coats AJS, Brunotte F, et al. Physical training improves skeletal muscle metabolism in patients with chronic heart failure. $₹ \mathrm{Am}$ Coll Cardiol 1993; with chron

42 Dubach P, Froelicher VF. Cardiac rehabilitation for heart failure patients. Cardiology 1989;76:368-73.

43 Rossi P. Physical training in patients with congestive heart failure. Chest 1992;101(suppl):350-3S.

44 Working Group on Rehabilitation of the European Society of Cardiology. Chronic heart failure. Eur Heart $f$ 1992;13(suppl. C):42-4

45 Coats AJS. Exercise rehabilitation in chronic heart failure. f Am Coll Cardiol 1993;22(suppl A):172-7A.

46 Dracup K, Walden JA, Stevenson L, Bracht ML. Quality of life in patients with advanced heart failure. foumal of Heart and Lung Transplantation 1992;11:273-9.

47 Mayou R, Blackwood R, Bryant B, Garnham J. Cardiac failure: symptoms and functional status. $\mathcal{f}$ Psychosom Res 1991;35:399-407.

48 Gorkin L, Norvell NK, Rosen RC, et al. Assessment of quality of life as observed from the baseline data of the studies of left ventricular dysfunction (SOLVD) trial quality-of-life substudy. Am $\mathscr{f}$ Cardiol 1993;71:1069-73.

49 Rector TS, Cohn JN. Assessment of patient outcome with the Minnesota living with heart failure questionnaire: reliability and validity during a randomized, doubleblind, placebo-controlled trial of pimobendan. Am Heart f 1992;124:1017-25.
50 Mumford E, Schlesinger HJ, Glass GV. The effects of psychological intervention on recovery from surgery and heart attacks: an analysis of the literature. $A m \mathcal{F}$ Public Health 1982;72:141-51

51 Rideout E. Chronic heart failure and quality of life: the impact of nursing. Canadian fournal of Cardiovascular Nursing 1992;3:4-8.

52 Guyatt GH. Methodological problems in clinical trials in heart failure. $\mathcal{F}$ Chron Dis 1984;38:353-63.

53 Feinstein AR, Fisher MB, Pigeon JG. Changes in dyspneafatigue ratings as indicators of quality of life in the treatment of congestive heart failure. $A m \mathcal{F}$ Cardiol 1989;64:50-5.

54 Stewart AL, Greenfield S, Hays RD, et al. Functional status and well-being of patients with chronic conditions. Results from the Medical Outcomes Study. $\mathscr{f} A M A$ 1989;262:907-13.

55 Rector TS, Kubo SH, Cohn JN. Validity of the Minnesota living with heart failure questionnaire as a measure of therapeutic response to enalapril or placebo. $A m \mathcal{F}$ therapeutic response to

56 Tandon PK, Stander H, Schwarz RP. Analysis of quality of life data from a randomized, placebo-controlled heartfailure trial. f Clin Epidemiol 1989;42:955-62.

57 Bulpitt $\mathrm{CH}$, Fletcher AE. Measurement of the quality of life in congestive heart failure. Influence of drug therapy. Cardiovascular Drugs and Therapeutics 1988;2: 419-24.

58 Permanyer-Miralda G, Alonso J, Antó JM, AlijardeGuimerà $M$, Soler-Soler $J$. Comparison of perceived health status and conventional functional evaluation in stable patients with coronary artery disease. 7 Clin Epidemiol 1991;44:779-86.

59 Cox J, Naylor D. The Canadian Cardiovascular Society grading scale for angina pectoris: is it time for refinements? Ann Intern Med 1992;117:677-83.

60 Cowley AJ, Stainer K, Wynne RD, Rowley JM, Hampton JR. Symptomatic assessment of patients with heart failure: double-blind comparison of increasing doses of diuretics and captopril in moderate heart failure. Lancet 1986;i:770-2.

61 Guyatt GH, Nogradi S, Halcrow S, Singer J, Sullivan MJJ, Fallen EL. Development and testing of a new measure of Fallen EL. Development and testing of a new measure of
health status for clinical trials in heart failure. $₹$ Gen health status for clinical
Intern Med 1989;4:101-7.

62 Rector TS, Johnson G, Dunkman WB, et al. Evaluation by patients with heart failure of the effects of enalapril compared with hydralazine plus isosorbide dinitrate on quality of life. V-HeFT II. Circulation 1993;87(suppl VI):VI-71-7. 